\title{
Solitary fibrous tumour of the pleura: A moving target
}

\author{
Mohammed H AlShati MD FRCPC FCCP
}

\section{CASE PRESENTATION}

A 52-year-old actively smoking woman was incidentally found to have a peripheral mass on plain chest imaging before employment (Figure 1A). A physical examination was unremarkable. A computed tomography scan revealed a large, well-circumscribed pleural-based mass on the left side (Figure 1B). During computed tomography-guided biopsy, with the patient in the right decubitus position however, the mass moved away from the pleura (Figure 1C). During surgical resection, the tumour was found to be partially located in the left major fissure and attached to the visceral pleura by a pedicle (Figure 2), allowing for its mobility. Histopathology confirmed the diagnosis of solitary fibrous tumour of the pleura (SFTP) without malignant features. Follow-up for two years revealed no recurrence.

SFTP is a rare neoplasm accounting for $<5 \%$ of primary pleural tumours (1) and affects both sexes equally, with a peak incidence in the sixth and seventh decades of life. In contrast to mesothelioma, most SFTPs are benign, asymptomatic, arise from mesenchymal cells, stain positively with CD34, and have no association with smoking or asbestosis.

A large, well-defined mass abutting the pleura is a common radiological finding (2). Nevertheless, this is nonspecific and may mimic mediastinal, chest wall or subpleural lung neoplasms. Approximately $40 \%$ of SFTPs are of visceral and peduncled type and may move in relation to body position - an overlooked sign that is useful for preoperative diagnosis.

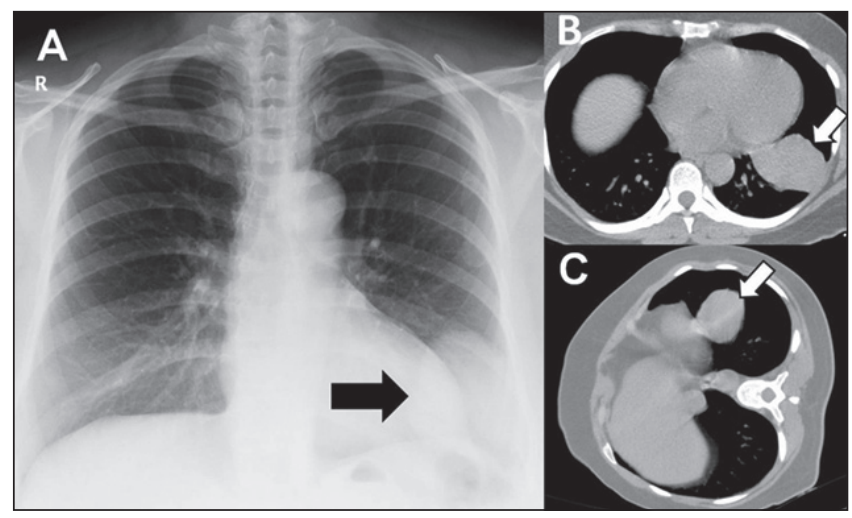

Figure 1) A Posteroanterior chest radiograph showing a well-defined periphral mass (arrow) on the left inferior hemithorax. B Unenhanced computed tomography scan (mediastinal window) demonstrating an oval soft-tissue mass (arrow) abutting the pleura with acute angles, mimicking a subpleural lung mass. Lobular mass borders are also apparent. C Demonstration of tumour movement away from the pleura while in the right decubitus position
Definitive diagnosis can be established by pathological examination of an adequate tissue sample, usually a resected tumour. Criteria for malignancy include high mitotic activity, presence of necrosis, nuclear atypia and pleomorphism (3). Paraneoplastic features described in association with SFTP include hypertrophic pulmonary osteoarthropathy ( $10 \%$ to $20 \%$ ) and refractory hypoglycemia $(5 \%)$. The latter is known as Doege-Potter syndrome and believed to be due to secretion of insulin-like growth factor.

Although complete surgical resection with negative margins is the treatment of choice, regional recurrence may occur and long-term follow-up is essential.

ACKNOWLEDGEMENT: The author thanks Dr Dherar AlShehab for providing the intraoperative surgical image.

\section{CONFLICT OF INTEREST/FUNDING: None.}

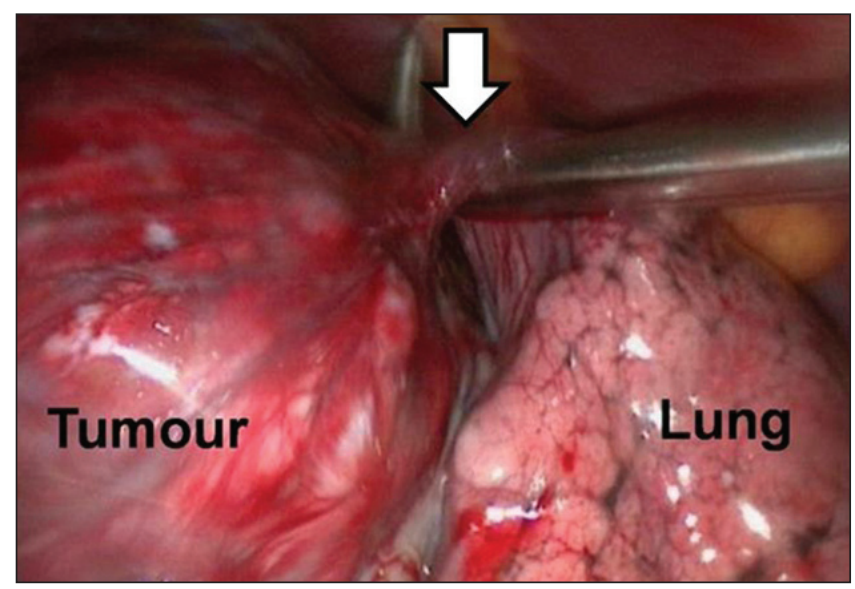

Figure 2) During video-assisted thoracoscopic surgery, the tumour appeared encapsulated, lobulated, whitish in colour and attached to the visceral pleura of the left lower lobe by a pedicle (arrow)

\section{REFERENCES}

1. Cardillo G, Lococo F, Carleo F, Martelli M. Solitary fibrous tumors of the pleura. Curr Opin Pulm Med 2012;18:339.

2. Cardinale L, Ardissone F, Garetto I, et al. Imaging of benign solitary fibrous tumor of the pleura: A pictorial essay. Rare Tumors 2010;31;2:e1.

3. Magdeleinat P, Alifano M, Petino A, et al. Solitary fibrous tumors of the pleura: Clinical characteristics, surgical treatment and outcome. Eur J Cardiothorac Surg 2002;21:1087-93.

\footnotetext{
The 'Images in Respiratory Medicine' section of the Canadian Respiratory Journal aims to highlight the importance of visual interpretation, whether physiological, radiological, bronchoscopic, surgical/thorascopic or histological, in the diagnosis of chest diseases. Submissions should exemplify a classic, particularly dramatic or intriguing presentation of a disease while offering an important educational message to the reader (insightful diagnostic pearls or differential diagnosis, etc). This section is not intended to be a vehicle for publication of case reports (see the Clinical-Pathologic-Conferences for case-based leaning series).
}

Division of Respirology and Sleep Medicine, Al-Adan Hospital, Ahmadi, Kuwait

Correspondence: Dr Mohammed H AlShati, Division of Respirology and Sleep Medicine, Al-Adan Hospital, PO Box 46969, Ahmadi,

Kuwait 64020. Telephone 965-9984-7409, fax 965-2396-8915, e-mail dr_alshatti@hotmail.com 


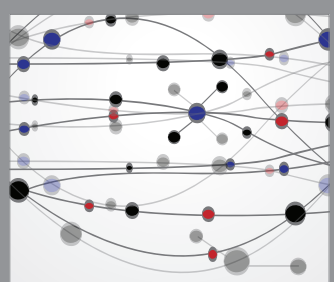

The Scientific World Journal
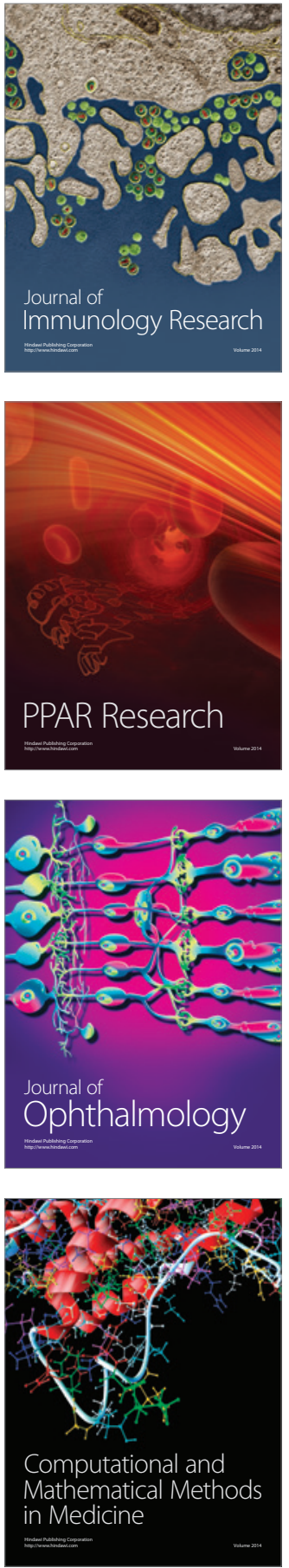

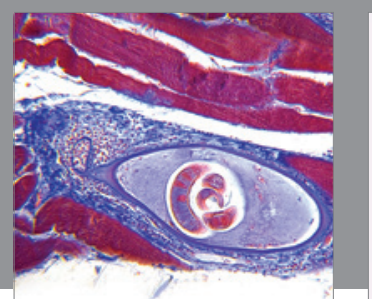

Gastroenterology Research and Practice

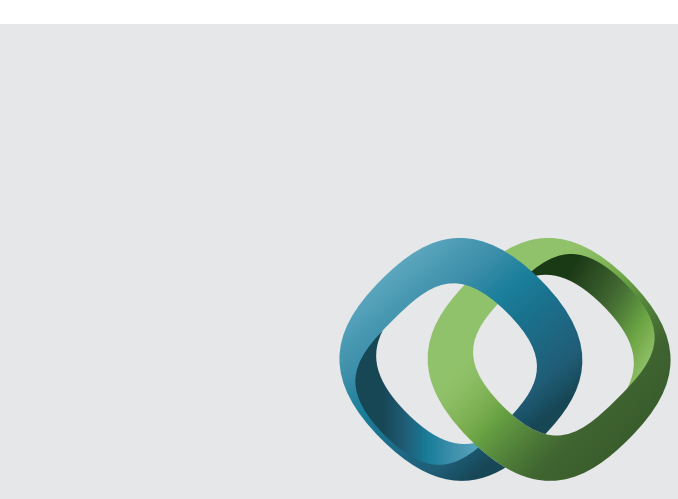

\section{Hindawi}

Submit your manuscripts at

http://www.hindawi.com
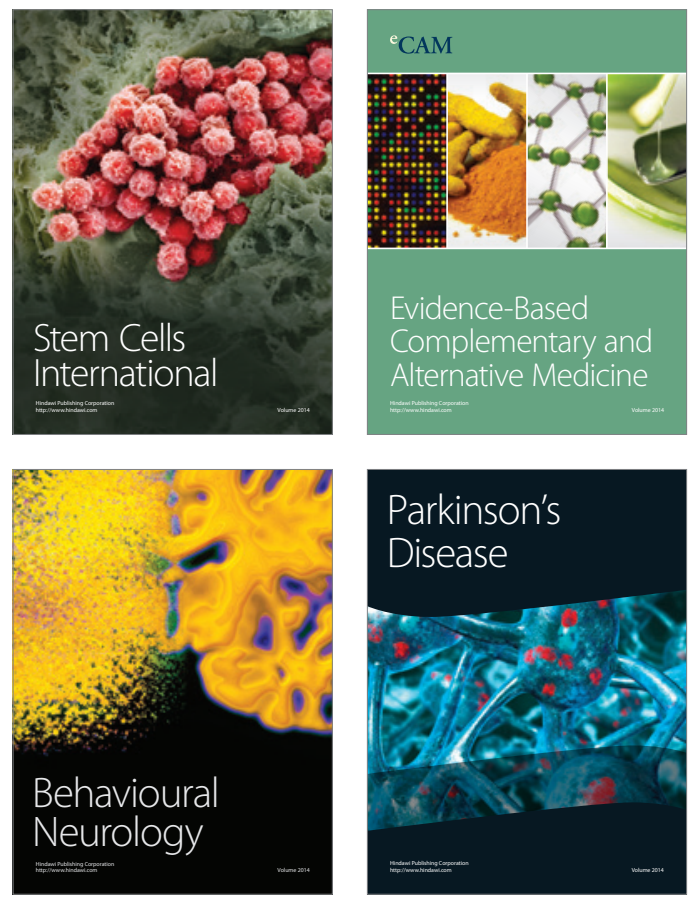
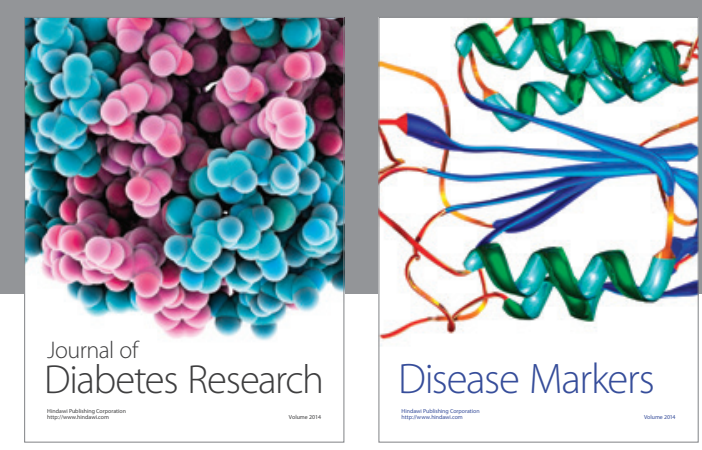

Disease Markers
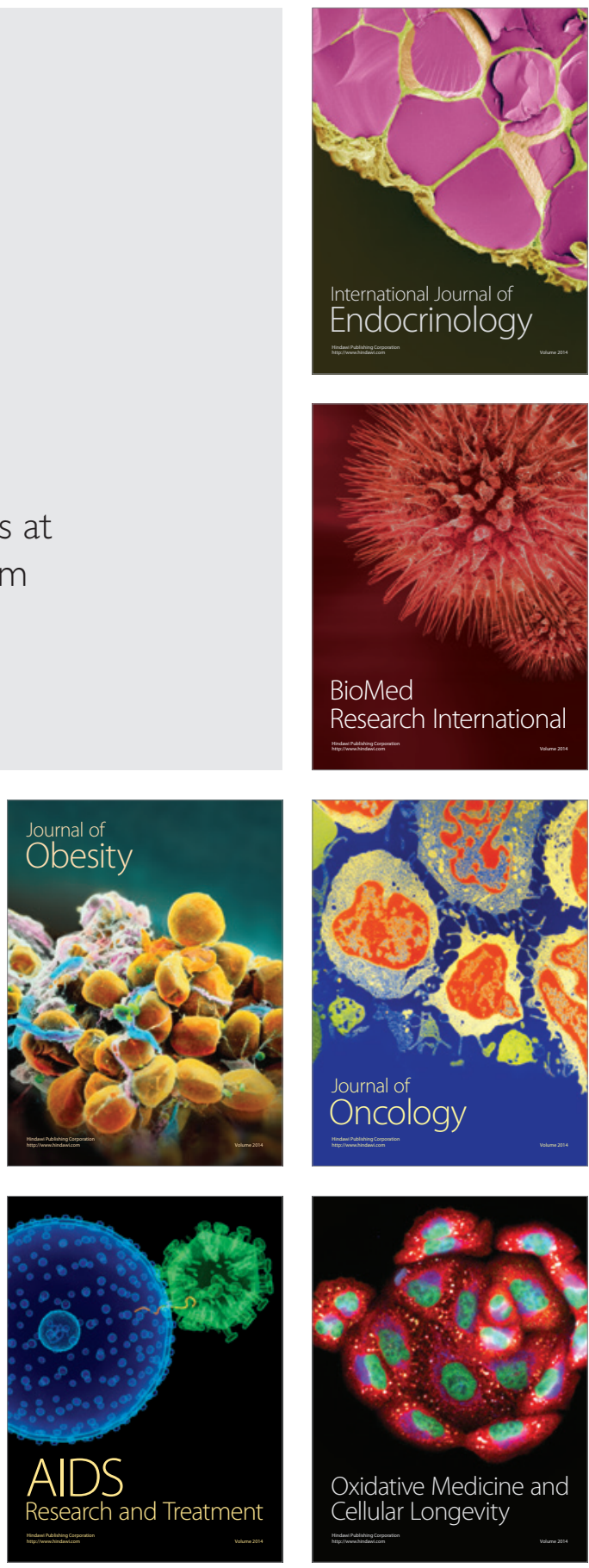